\title{
Measurement Scale Development and Validation of Female Employees' Career Expectations in Mainland China
}

\author{
Ting Liu ${ }^{1,2}$, Huawen Shen ${ }^{2, *}$, Ka Yin Chau ${ }^{2} \mathbb{D}$ and Xin Wang ${ }^{2}$ \\ 1 Tourism College, Huangshan University, Anhui 245000, China; 13855913660@163.com \\ 2 Faculty of International Tourism and Management, City University of Macau, Macau, China; \\ gavinchau@cityu.mo (K.Y.C.); xwang@cityu.mo (X.W.) \\ * Correspondence: jamesshen@cityu.mo; Tel.: +86-1385-591-3660
}

Received: 15 April 2019; Accepted: 20 May 2019; Published: 23 May 2019

\begin{abstract}
This paper aimed to develop a measurement scale for female hotel employees' career expectations. Both qualitative and quantitative research methodologies were applied. In-depth interviews were first conducted to collect primary data of career expectation activities, and then the main survey was conducted nationwide to collect representative data. After a series of exploratory factor analysis, two dimensions were extracted, namely career rewards and career development. The results of confirmatory factor analysis indicated that the measurement items developed were both reliable and valid. Of the two factors of female hotel employees' career expectations, career rewards was an important factor. Both academic and practical implications were discussed to provide valuable insights for human resource management of hotels in China. The paper concludes with the discussion of limitation and suggestions for future research.
\end{abstract}

Keywords: career expectation; measurement scale; factor analysis; female hotel employee

\section{Introduction}

The sustainable development of human resources is very crucial for the development of an organization. The organizations that consider sustainable development to be a very important objective may attract top talent. It can also help employees achieve sustainability, and do their best to minimize waste in the organization. With the increasing importance and number of female employees in the hotel industry, understanding the career expectations of female employees is of great significance for sustaining the development of a hotel organization.

Expectation is a belief about the possibility of future events [1] and the expectation of what will happen [2]. Generally speaking, when employees start to work in the workplace, they start to set an expectation for future career development according to their life experience, career ambition and personal characteristics [3]. There is also some valuable information on career expectations from the perspective of new entrants [4]. According to the expectancy confirmation theory [5], expectation and satisfaction are related. The study has confirmed that career expectation is an important factor affecting employee turnover rate [6]. For new employees, a clear understanding of their future career expectations will effectively reduce their turnover rate [7]. It is found that the quality of a person's work and family relationship is jointly influenced by his/her work experience and future career expectations [8].

Women's attitude toward future career development is not so "ambitious" compared with men. This feature is the same for men and women in all positions and ranks. Female employees have weak management motivations. They don't have the motivation to study advanced technology, and they 
do not want to work hard at high-level positions. Even though they want to achieve better career advancement, they do not have the positive attitude to do this actively [9]. The reasons are mainly due to the influence of traditional Chinese gender division of labor and family concept. Women's sense of self is weakened, and they are emotionally, psychologically and physically dependent on men, lacking achievement motivation, enterprise and self-reliance [10].

Everyone's career goals are influenced by his or her personal expectations and values. Personal expectations and values will influence the individual's goals and pursuit of different roles. The degree of realization of goals will determine the individual's status and role in social life, thus shaping his or her role behavior. There is a big difference between the behavior of family women and career women in social life. The values of family women often focus more on family happiness, a happy family is the primary goal of life and the standard of living a happy life, so the pursuit of a happy family is the biggest goal in life. Conversely, female high-fliers value job performance and pay more attention to their own careers, so professional advancement is regarded as the most important task. Compared with men, women tend to shrink back in the pursuit of career success. They are not willing to engage in challenging work, and their subjective attitude towards promotion and career success is not as positive as that of men, so they are likely to lose many opportunities for promotion [11].

Nowadays, more and more professional women value the success of both family and career in their life, which shows their recognition of the dual roles of family and career. This is much more obvious in female employees at hotels, the professional characteristics of female hotel employees determine that their career will encounter many obstacles and difficulties, if they want to achieve long-term career development and promotion, women need to have a positive and optimistic attitude, to build a good interpersonal relationship network and to overcome their own weak personality. Women need to make continuous progress, participate in various training and learning, establish correct career expectations, break through career development restrictions, and take the initiative to plan their career development, so as to achieve career success [12].

$\mathrm{Li}$ (2014) also pointed out that female employees hope that they can bear the burden of family and work relying on their own efforts [13]. If they can achieve a win-win situation of family happiness and sustainable career development, they will gain social respect. This also requires them to constantly improve themselves and establish good life values. One of the reasons why the female hotel managers suffered a bottleneck was the lack of career expectations of women [14]. According to the survey results of Lin (2015), with the increase of age and the enrichment of social experience, female hotel employees are becoming less and less enthusiastic for their work, and even have a strong sense of job burnout, resulting in low work efficiency and professional competitiveness, etc. [15]. After their career developed to a certain extent, many women's self-awareness is likely to become blurred, and career expectations are reduced. If career development is not smooth, many women will question their own abilities. They are no longer actively pursuing success, and are even reluctant to advance because they are afraid of their own abilities.

\section{Research Gap}

Although scholars around the world started late in discussing career expectations, some achievements have been made. Relatively speaking, the empirical conclusions obtained are relatively simple. In particular, compared with foreign research results, the research of Chinese scholars on career expectations is relatively backward, with limitations and deficiencies. It is mainly reflected in the following aspects:

First, the definition of the concept of career expectations has not yet formed a unified standard. At present, the research on the concept of career expectation is mainly defined from the perspective of personal career beliefs and goals, as well as the distinction from other similar concepts, and no authoritative and unified opinions have been formed. On the one hand, most of the domestic theoretical research on the concept of career expectation draws on the relevant research results of foreign scholars. Due to the differences in cultural tradition and reality, there are still great differences between Chinese 
and Western employees in career expectation. On the other hand, the concept of career expectation is often confused with the concept of career values, career aspirations, career ideals, etc., and there is overlapping content, without a clear definition. Therefore, further research is needed to form clear and definite categories, so as to provide reliable references for structural measurement research and related factors research $[16,17]$.

Second, the division of the structural dimensions of career expectations has not yet formed a unified conclusion. The dimensionality division of career expectation is not consistent with practice, and it is often mixed with other measurement tools. Domestic empirical research on employee career expectation mostly adopts the scale of career expectation developed by $\mathrm{Wu}$ and $\mathrm{Li}$ [18]. Although this scale has good reliability and validity, there are still many problems to be improved in terms of item quantity and content. Although the scale developed by Ling, Fang and Bai (1999) was widely used in the research on occupational expectation of domestic employees, it was also used to measure occupational values and could not scientifically and rigorously measure the occupational expectation status of employees [19]. Therefore, further research should be carried out on the development of career expectation scale to develop a scale that is suitable for Chinese national conditions and can reflect the characteristics of Chinese employees. It needs to be pointed out that no matter if it is Western research or domestic research, there is no developed scale specifically for measuring the career expectations of female hotel employees in the context of Chinese culture.

Third, there is a lack of research on the career expectations of employees after they enter a company. At present, most of the research on career expectations focus on the career goals and choices of individuals before entry, mainly focusing on demographic variables, such as gender, family background and education level. There are few studies on the career expectation of employees after they enter a company, and there will inevitably be psychological changes after they enter a company. There are few studies on the influence of behavioral changes caused by such psychological changes on their career expectations, which can be further studied in the future.

The rapid development of the hotel industry in mainland China needs a large number of qualified personnel and female employees are an important part of a hotel's human resources. Career management is the key aspect of human resource management in hotels, as a result, China's hotel industry should support the staff's career development agenda, especially female employees [20]. However, the career expectation management of female hotel employees in mainland China has not been fully paid attention to and studied. Although some scholars have conducted research on occupational expectation, they have also summarized specific occupational expectation scale [19,21]. However, most of these measures are implemented in Western countries, which may not be in line with China's national conditions, and there is no specific scale for the career expectations of female hotel employees in mainland China. Therefore, it is necessary to develop a structural dimension to measure the career expectations of female hotel employees in mainland China, and provide scientific guidance for the practice of hotel human resource management.

\section{Research Methodology}

This study aims to explore the career expectation (CE) activities practiced by hotels in China, and to develop a sound and reliable measurement of $\mathrm{CE}$ activities. First, a qualitative research methodology was used to investigate such activities. In-depth interviews based on a semi-structured questionnaire were conducted with the female employees of the hotels. The data collected were consolidated and content analyzed. The internal reliability and construct validity were examined by conducting both exploratory factor analysis (EFA) and confirmatory factor analysis (CFA).

The current study is aimed at female employees working in three-star or above hotels in mainland China, mainly at the grass-roots level and middle level. The survey shows that the middle and senior managers of hotels in mainland China are between 25 and 40 years old [22], and 58\% of them have obtained professional experience related to higher education and the hotel industry [23]. Super (1957) points out that individuals experience five career stages in their career, namely growth, exploration, 
establishment, maintenance and decline [24]. According to this theory, individuals between the ages of 25 and 44 are in the career-building stage. At this stage, people are concerned about their career prospects. They are working hard to establish a stable working environment with growth potential and promotion opportunities. For many people in a variety of occupations, the decade between the ages of 30 and 40 is one of the fastest growing. In hotels of mainland China, female employees at the grass-roots level and middle level constitute the main force of the hotel staff team. Therefore, the target population of this study is female employees aged 25-40 at the grass-roots and middle levels of the hotel. In order to collect representative data sets, the convenience sampling method was used in this study.

Following the procedure recommended by Churchill (1979), which is shown in Figure 1, the scale development included five major steps: (1) specifying domain of the construct, (2) developing initial items; (3) purifying measures; (4) collecting data; and (5) assessing the validity and reliability of the proposed measurement scale [25].

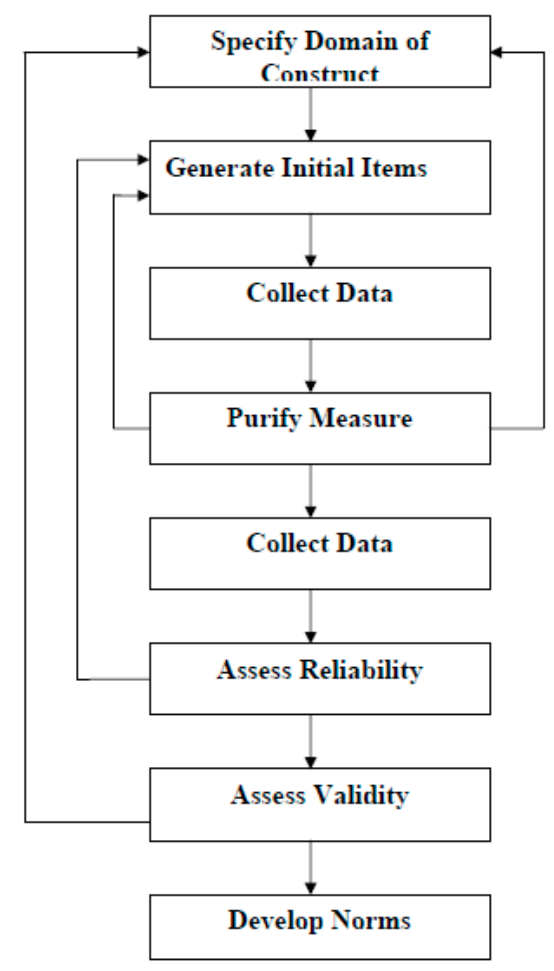

Figure 1. Suggested procedure for instrument development.

\section{Specifying Domain of the Construct}

A construct is an abstract theoretical concept that is generated to explain a phenomenon, and sound construct measurement is the basis of scientific advancement [26]. The first step in developing a measurement scale is to specify the domain of the construct. That is, the researcher should be clear about "what is included in the definition and what is excluded" [25], (p. 67).

Western scholar Gottfredson (2005) believes that "career expectation refers to the process in which an individual continuously coordinates his personal factors such as ability, hobbies and values with occupational opportunities, social needs and other environmental factors, and generates self-cognition and self-positioning" [27]. Chinese scholar Ling et al. (1999) argued that "occupational expectation refers to individual's yearning and desire for a certain occupation, and it is a belief and attitude of individual towards occupation; Career expectation belongs to the category of individual tendency, is the external form of individual career values, and is the reflection of individual world outlook and outlook on life" [19]. Previous research results are suitable for a wide range of human resource 
management, but the research on career expectations of China's hotel industry is very limited. This study will focus on the following two aspects: (1) to explore the career expectations of female hotel employees in mainland China; (2) clearly defined practical activities related to career expectations.

\section{Developing Initial Items}

Instrument development generally involves two stages: a literature review and personal interviews. In this study, an extensive literature review was conducted to identify relevant career expectation practices. As noted, many studies of CE activities have been undertaken in Western countries. However, career expectation is still a relatively new phenomenon in China, which has not attracted sufficient attention from the industry and scholars, and relevant research is also very limited. Hence, it is of great theoretical and practical significance to comprehensively investigate the career expectation of women in hotels and develop a scientific measurement scale.

As there are very few studies on career management of the hotel industry, it is difficult to provide effective theoretical reference. Therefore, this paper expands the scope of literature review and sorts out the beneficial data of this study from a wide range of management literature. Literature research analyzed and sorted out a large number of scholars' previous studies on career expectation [18,28-31]. The research of Wu and $\mathrm{Li}$ (2001) shows that "career expectation of college students can be divided into three dimensions, namely prestige, status and stability, intrinsic value and extrinsic value" [18]. Yang (2010) analyzed three factors: prestige, welfare and development [32]. Liu (2007) divided career expectation into three dimensions in her research, "external value, internal value and prestige status" [33]. Through systematic literature analysis, the scale of career expectation developed by Wu and $\operatorname{Li}(2001)$ was finally determined as the literature reference of this study. The scale reflects the characteristics of career expectation of Chinese employees, has good reliability and validity, and is widely used in the study of career expectation of employees in various industries in China. Specific items are shown in Table 1. During the interview, the researcher also made a detailed explanation of each career expectation as a reference, which will also provide materials for the in-depth interview of this study.

Table 1. Career expectation (CE) items of $\mathrm{Wu}$ and $\mathrm{Li}(2001)$ [18].

\begin{tabular}{l} 
Scale Items \\
\hline 1. High income \\
2. Good welfare \\
3. Stable career \\
4. Educational opportunities \\
5. Have the opportunity to go abroad \\
6. High social status \\
7. Can use your talents \\
8. Provide social insurance, housing fund \\
9. Elegant work environment \\
10. In line with interest \\
11. Equal opportunity, fair competition \\
12. Promotion opportunities \\
13. High visibility of the unit \\
14. Large organization size \\
15. Use what you learn \\
16. Convenient transportation and unimpeded information \\
17. Autonomy and freedom \\
18. Challenging work \\
19. Easy to be famous \\
20. The organization has high level \\
21. In big cities
\end{tabular}


After analyzing the literature, in-depth interviews were conducted. Personal interviews collected information from two aspects: first, collected information from grassroots female employees of the hotel to determine their career expectations; the second is the survey of middle managers and supervisors to obtain the CE information about the mid-level female hotel staff. The results of the two round interviews are complementary to each other and can fully reflect the specific career expectations of female hotel employees in mainland China. In the first round of interviews, a total of 16 grassroots female hotel employees were interviewed. In order to make the sample representative, female employees from different regions and star-rated hotels were invited to participate in the interview, so as to collect preliminary information about career expectations. The female employees participating in the interview are from four four-star or five-star hotels in Huangshan, Shanghai and Wuhan. They are between 20 and 48 years old and come from various departments of the hotels. The reason why grassroots female employees were chosen is that they are not only full of expectations for their career development, but also feel confused and uncertain. They care about their career development, so they can provide valuable information for this study. Through in-depth interviews, the aim was mainly to understand the specific career expectations of female hotel employees and whether these expectations can be realized in their future career development. The participants in the second round of interviews were eight department managers or supervisors from four- or five-star hotels in Huangshan and Shanghai respectively. The selection of mid-level hotel managers to participate in the interview is to understand the change of career expectations of female employees at this stage from the perspective of mid-level managers. The profile of the interviewees as shown in Table 2.

Table 2. The profile of the interviewees.

\begin{tabular}{ccc}
\hline Round & Number & Rank \\
\hline 1 & 16 & grassroots female hotel employees \\
2 & 8 & department managers or supervisors \\
\hline
\end{tabular}

All interviews were first conducted in the form of an open questionnaire, and each respondent was asked to write down her specific thoughts on career expectations. In order to describe the difference between different literatures in Chinese and Western research results, the researcher explained the sentences in the literature to the respondents. According to the responses of 24 respondents, a total of 27 items were obtained, as shown in Table 3.

Table 3. CE items generated from the in-depth interviews.

\begin{tabular}{l} 
Scale Items \\
\hline 1. I expect a good salary for my job \\
2. I expect good job benefits \\
3. I expect a stable career \\
4. I expect to have many opportunities for education and training \\
5. I expect the hotel to provide an opportunity to go abroad \\
6. I want to have a higher social status \\
7. Expect to be able to use your talents at work \\
8. Expect the hotel to provide social insurance, housing fund and other benefits \\
9. Want an elegant work environment \\
10. I am looking for a career that suits my interests \\
11. Expect equal opportunity and fair competition \\
12. Expect more opportunities for advancement \\
13. It is important to me that the hotel is well known \\
14. I hope the hotel I work in is a medium or large scale hotel \\
15. Use what you learn \\
16. Convenient transportation and unimpeded information \\
17. Work autonomously and freely \\
\hline
\end{tabular}


Table 3. Cont.

\begin{tabular}{l} 
Scale Items \\
\hline 18. Want a challenging job \\
19. Easy to be famous \\
20. Expect to work in a high-star hotel \\
21. Hope to work in a hotel which is in the first and second tier cities \\
22. Good relationship with colleagues * \\
23. Superior cares about employees * \\
24. Expect to fully learn knowledge of other departments of the hotel and fully understand the working \\
process of each department* \\
25. Deep understanding of the hotel culture and the future of the industry * \\
26. Obtain the ability to work at higher levels through training and learning * \\
27. Low job variability*
\end{tabular}

${ }^{*}$ represents items developed in this study.

Data analysis and coding were conducted following the process recommended by Auerbach \& Silverstein (2003) [34]. In phenomenological research, the researcher attempts to acquire a greater understanding of what participants' mean and seek insight into the phenomena by reference to the data collected. By trying to understand and interpret what is occurring and why, the researcher can develop ideas based on the collected information [35]. The data of the in-depth interviews were summarized and sorted out and compared with the items listed in the literature. The results show that the career expectations of employees in the general industry are almost all met in the hotel industry, and some expectations are not very obvious in the hotel industry. In addition, interviewees generally describe the career expectation phenomenon that some hotel employees attach great importance to. For example, the female employees all showed a high recognition of their career prospects, and generally expressed an urgent need to improve their ability and knowledge. In terms of "I expect the hotel to provide an opportunity to go abroad", "I want to have a higher social status", "Work autonomously and freely" and "Easy to be famous", they generally show a neutral attitude. "I expect to have many opportunities for education and training" and "Expect to fully learn knowledge of other departments of the hotel and fully understand the working process of each department" are similar, which are merged into "Many training opportunities and comprehensive training content". After comprehensive induction, analysis and consolidation, 22 career expectation items were obtained, as shown in Table 4 below.

Table 4. Initial CE items based on the literature review and in-depth interviews.

\begin{tabular}{l} 
Scale Items \\
\hline 1. I expect a good salary for my job \\
2. I expect good job benefits \\
3. I expect a stable career \\
4. Many training opportunities and comprehensive training content \\
5. Expect to be able to use your talents at work \\
6. Expect the hotel to provide social insurance, housing fund and other benefits \\
7. Want an elegant work environment \\
8. I am looking for a career that suits my interests \\
9. Expect equal opportunity and fair competition \\
10. Expect more opportunities for advancement \\
11. It is important to me that the hotel is well known \\
12. I hope the hotel I work in is a medium or large scale hotel \\
13. Use what you learn \\
14. Convenient transportation and unimpeded information \\
15. Want a challenging job \\
16. Expect to work in a high-star hotel
\end{tabular}


Table 4. Cont.

\begin{tabular}{l} 
Scale Items \\
\hline 17. Hope to work in a hotel which is in the first and second tier cities \\
18. Good relationship with colleagues * \\
19. Superior cares about employees * \\
20. Deep understanding of the hotel culture and the future of the industry * \\
21. Obtain the ability to work at higher levels through training and learning * \\
22. Low job variability * \\
${ }^{*}$ represents items developed in this study.
\end{tabular}

\section{Purifying the Measures}

After determining the content of 22 career expectations, it is also necessary to determine their effectiveness. Firstly, the logical analysis method is used to analyze and evaluate the content validity. It is mainly for researchers or experts to judge whether the content of the question can achieve the purpose of measurement and whether it can meet the measurement requirements. The specific approach is to invite five hotel general managers (deputy general managers) as the hotel industry experts to participate in the evaluation, because they have a wealth of hotel management experience. According to their comments and suggestions, the scales listed were modified. "I expect good job benefits" and "Expect the hotel to provide social insurance, housing fund and other benefits", because both are descriptions of the problem of welfare benefits are combined to form the following statement: "Expect good job benefits". "I expect a stable career" is similar to "Low job variability", which is merged into "High job stability". Both "Expect equal opportunity and fair competition" and "Expect more opportunities for advancement" reflect the expectation of fair promotion opportunities, so they are also summed up as "Expect more promotion opportunities through fair competition". "It is important to me that the hotel is well known", "I hope the hotel I work in is a medium or large scale hotel" and "Expect to work in a high-star hotel" were merged, because they all described the grade of the hotel, forming the following statement: "I hope to work in a famous, medium or large hotel with more than four stars". As talent also includes personal interests and hobbies, "Expect to be able to use your talents at work" and "I am looking for a career that suits my interests" is merged into "Expect to incorporate their interests and talents in their work".

Subsequently, four experts from the hospitality industry were invited to analyze these initial measurement items by scoring. They rated each item on a seven-point scale $(1=$ very unrepresentative, $7=$ very representative) [36]. According to the score results, the measurement items with the average value higher than four were kept ("Use what you learn" "Convenient transportation and unimpeded information" "Deep understanding of the hotel culture and the future of the industry" were excluded because they were all lower than 4 points). After the evaluation by both the hotel industry and academic experts, the number of measurement items was reduced to 13. The remaining projects are comprehensive and concentrated, reflecting the career expectations of female hotel employees in mainland China. The updated list is shown in Table 5.

Table 5. Updated scale items of CE.

\begin{tabular}{ll}
\hline No. & Scale Items \\
\hline CE1 & I expect a good salary for my job \\
CE2 & Expect good job benefits \\
CE3 & High job stability \\
CE4 & Many training opportunities and comprehensive training content \\
CE5 & Expect to incorporate their interests and talents in their work \\
CE6 & Want an elegant work environment \\
CE7 & Expect more promotion opportunities through fair competition \\
\hline
\end{tabular}


Table 5. Cont.

\begin{tabular}{ll}
\hline No. & Scale Items \\
\hline CE8 & I hope to work in a famous, medium or large hotel with more than four stars \\
CE9 & Want a challenging job \\
CE10 & Hope to work in a hotel which is in the first and second tier cities \\
CE11 & Good relationship with colleagues * \\
CE12 & Superior cares about employees * \\
CE13 & Obtain the ability to work at higher levels through training and learning * \\
\hline
\end{tabular}

* represents items developed in this study.

The purified items were developed into statements as follows.

1. I expect to have a good salary for my job.

2. I expect to have good job benefits.

3. I expect to have a high job stability.

4. I expect to have many training opportunities and comprehensive training content.

5. I expect to incorporate my interests and talents in my work.

6. I expect to work in an elegant environment.

7. I expect to have more promotion opportunities through fair competition.

8. I hope to work in a famous, medium or large hotel with more than four stars.

9. I want to have a challenging job.

10. I hope to work in a hotel which is in the first and second tier cities.

11. I expect I will have a good relationship with colleagues.

12. I hope my superior cares about employees.

13. I can obtain the ability to work at higher levels through training and learning.

\section{Test Reliability and Validity}

The developed measurement items were designed into questionnaires and a pilot test was conducted. First, 10 female hotel employees were asked to make a preliminary evaluation of the questionnaire and make adjustments accordingly. The pilot test was conducted in Anhui Province and Zhejiang Province in mainland China. A total of seven hotels were selected. In each selected hotel, contacts were identified to distribute the questionnaire, and finally a total of 219 questionnaires were collected. Through the processing of the questionnaire data, the results show that the overall effect of the questionnaire quality is ideal except that some words needed to be improved. Therefore, after the improvement of the questionnaire, the formal questionnaire was determined.

\subsection{Respondent Profile}

The target respondents of the current study were female employees who worked in four or five star hotels in mainland China. Main survey data were collected from more than 10 provinces, cities and regions in mainland China. Participants' age, education level, job position, working years and work experience were different. As female hotel employees are the dominant force in the hotel industry in mainland China, the data collected can reasonably represent the situation of female hotel employees in mainland China. Table 5 shows the demographic characteristics of respondents. Of the 525 respondents, more than $72 \%$ were between the ages of $23-44$, more than $56 \%$ were married and about $69 \%$ had completed a college education or higher, indicating that the majority of respondents were well educated. The majority of the respondents $(76 \%)$ were supervisors or below, and about $61 \%$ had more than 4 years of hotel work experience on average. They work in all major hotel departments including: food and beverage (25.9\%), front office (19.62\%), human resources (19.24\%), housekeeping $(12.76 \%)$, sales and marketing $(8.38 \%)$, finance $(7.05 \%)$, recreation $(1.14 \%)$, security $(0.95 \%)$ and other 
departments (4.95\%). Among the hotels surveyed, 9.71\% are three-star hotels, $19.24 \%$ four-star hotels and $71.05 \%$ five-star hotels.

\subsection{Exploratory Factor Analysis}

Exploratory Factor Analysis (EFA) was used to purify the measurement. Several criteria were considered for factor extraction. First, one of the most common criteria for addressing the number of factors is to retain factors with eigenvalues greater than 1 [37]. Second, a factoring loading of less than 0.40 is used as the cut-off point for factor interpretation [38]. Items with factor loadings that are greater than 0.40 in more than one component are removed to avoid cross loading [39]. Third, although factor loadings are useful, factor selection should not be based on this criterion alone. Communality and screen plots should also be used for factor extraction. For a sample size that is larger than 250, the average communality should be greater than 0.60 [40]. Fourth, the Corrected Item-Total Correlation value indicates the correlation between each item and the total score for the questionnaire. In general, corrected item-to-total correlation values that are less than 0.30 are deemed unacceptable [41]. Finally, Cronbach's alpha is calculated to measure the scale reliability for the factors identified, with 0.70 the minimum acceptable value.

EFA was applied to identify groups of variables and to reduce a dataset to a more manageable size by retaining as much of the original information as possible. The varimax rotation method was selected because it is a good general approach to simplify the interpretation of factors [41]. Based on the criteria listed for EFA, an iterative process was conducted to eliminate cross loading items and those with low factor loading and low item-to-total scores until the acceptable factors were obtained.

After EFA analysis, "CE4 Many training opportunities and comprehensive training content", "CE5 Expect to incorporate their interests and talents in their work", "CE6 Want an elegant work environment", "CE7 Expect more promotion opportunities through fair competition", "CE11 Good relationship with colleagues", "CE12 Superior cares about employees" had cross loading, therefore, they were deleted. Two factors were extracted from the remaining seven CE items. As shown in Table 6, Bartlett's test of sphericity was significant and the Kaiser-Meyer-Olkin (KMO) measure of sampling adequacy was 0.826 , indicating that the patterns of correlations were relatively compact and that generated distinct and reliable factors [41]. Cronbach's alpha of the total scale was 0.823 , and for the two factors it ranged from 0.740 to 0.881 , exceeding the minimum standard for reliability $(0.70)$ recommended by Nunnally (1978) [42]. It can therefore be concluded that the items comprising the two dimensions were internally consistent and stable and together formed a reliable scale.

Table 6. The results of exploratory factor analysis of career expectation.

\begin{tabular}{ccccc}
\hline Item & Factor & Eigenvalue & Variance Explained (\%) & Reliability Alpha $(\alpha)$ \\
\hline Factor 1: Career rewards & & 3.606 & 51.521 & 0.881 \\
CE1 & 0.873 & & & \\
CE2 & 0.908 & & & \\
CE3 & 0.843 & 1.262 & & \\
Factor 2: Career development & & & & \\
CE8 & 0.712 & & & \\
CE9 & 0.820 & & & \\
CE10 & 0.668 & & & \\
CE13 & 0.767 & & & \\
\hline
\end{tabular}

Kaiser-Meyer-Olkin $(\mathrm{KMO})=0.826$, Bartlett's Test of Sphericity: Chi-square $=1640.789, \mathrm{df}=21, p<0.000$.

\subsection{Confirmation Factor Analysis}

EFA has identified the structure of two dimensions. For complex models with multiple levels of potentially variable structure, it is important to examine each level separately to ensure that the identification can be verified [43]. Career Expectation is a multi-dimensional structure consisting of two dimensions measured by seven items. 
All indexes of goodness of fit $(\chi 2=30.754, \mathrm{df}=13, \chi 2 / \mathrm{df}=2.366, \mathrm{CFI}=0.989, \mathrm{GFI}=0.983$, RMSEA $=0.051)$ indicated that the fit between the model and the sample data was acceptable. According to Hair et al. (2009) [44], the validity of the measurement model depends on two aspects: (1) establishing an acceptable level of goodness of fit for the measurement model; (2) to find concrete evidence of construct validity.

The convergent validity of occupational expectations was evaluated by the magnitude of factor loading and its statistical significance level. Table 7 shows estimates, standardized factor loads, critical ratio (C.R.) and squared multiple correlations (SMC) between each variable and the others. The factor loading of "CE10 Hope to work in a hotel which is in the first and second tier cities" is 0.456 , slightly lower than 0.6 , and the standardized load estimate of all other factors is over 0.6, which is statistically significant (C.R. value is higher than 1.96) [43]. Thus, it can be seen that the convergent effectiveness of career expectation is satisfactory $[44,45]$.

Table 7. Confirmatory factor analysis (CFA) results for $\mathrm{CE}(\mathrm{N}=525)$.

\begin{tabular}{ccccc}
\hline & Estimate & C.R.(t-Value) & Std.Factor Loading & SMC \\
\hline Factor 1: Career Rewards & & & & 0.830 \\
Rewards -> CE1 & 1.000 & & 0.902 & 0.688 \\
Rewards -> CE2 & 0.941 & 23.365 & 0.820 & 0.672 \\
Rewards -> CE3 & 0.808 & 21.436 & & 0.524 \\
Factor 2: Career Development & & & 0.724 & 0.523 \\
Development -> CE8 & 1.000 & & 0.723 & 0.208 \\
Development -> CE9 & 1.121 & 14.502 & 0.456 & 0.670 \\
Development -> CE10 & 0.929 & 9.409 & 0.819 & \\
Development -> CE13 & 0.986 & 15.549 & & \\
\hline
\end{tabular}

Average variance extracted (AVE) was also used to test the convergent validity and discriminant validity. As shown in Table 8, all AVE values are basically greater than or equal to 0.50, with good convergence validity. In addition, the AVE of each construct was greater than the square correlation coefficient between corresponding constructs, verifying the satisfactory discriminant validity [46].

Table 8. Correlations (squared correlation), reliability, average variance extracted (AVE), and mean.

\begin{tabular}{ccc}
\hline Factor & Rewards & Development \\
\hline Rewards & 1.000 & \\
Development & $0.571(0.326)$ & 1.000 \\
C.R. & 0.888 & 0.781 \\
AVE & 0.725 & 0.481 \\
Mean & 6.336 & 6.100 \\
Std.Dev & 1.053 & 0.896 \\
\hline
\end{tabular}

Note: All are significant at the 0.001 level.

\section{Discussion}

Research on career expectations has been carried out for many years and has yielded some excellent results. However, most of these studies focus on the young generation's expectation of their future career $[16,18,33,47,48]$ and some other studies are on employees of Chinese enterprises [18,31], but it is not completely applicable to the career development of hotel employees, in particular the research on the career expectations of female hotel employees in mainland China is weak. Therefore, it is necessary to explore the career expectation scale for female hotel employees in mainland China. 
In this study, a scale for measuring career expectations of female hotel employees in mainland China was developed by combining qualitative research with quantitative research. The measurement scale was developed in four steps: developing initial items, refining measurement values, data collection, and evaluating the reliability and effectiveness of the proposed measurement scale. A total of 13 items were identified based on literature review and in-depth interviews, and then developed into questionnaires for formal investigation. Factor analysis of these 13 items produced two dimensions of effective and meaningful career expectations: career reward and career development.

The exploratory factor analysis results show that six items cannot meet the measurement requirements. After deleting the six items according to the statistical significance, the remaining seven items show a high level of internal consistency in two dimensions, and the reliability estimation range is 0.740 and 0.881 . AVE of the two dimensions is more than 0.50 and larger than the square value of the correlation coefficient between the corresponding dimensions, reflecting good convergent validity and discriminant validity [46]. Therefore, the proposed career expectation measurement scale for female hotel employees in mainland China is reliable and effective. Among the two dimensions, occupational remuneration is an important factor of occupational expectation.

This survey result is relatively consistent with the previous research results [14]. Employees are eager to receive continuous education and training and obtain opportunities to further improve their abilities. Career development is one of the biggest motivators for hotel employees [49]. Therefore, hotel managers must develop various training programs. Vocational training should be carried out in conjunction with other career development activities to meet the long-term career aspirations and expectations of employees, thus helping hotels to attract and retain outstanding female employees.

\section{Conclusions}

What does sustainable development mean for women? It takes gender equality and women's empowerment as separate goals. The study of this will create conditions and favorable environment for women to create the sustainable development, and help them to realize their life value, and give full credit to the indispensable role of women in the reform of global governance systems.

Influenced by traditional culture and social concepts, the career development of female hotel employees still has a long way to go. Hotel managers' consciousness of the importance of female employees directly determines the future direction of development, therefore, establishing an effective strategy specifically for female employees is one of the driving factors of the success of hotels in the future. This can help retain outstanding female talent which accounts for more than half of hotel staff.

This study makes a unique theoretical contribution to the research by developing a two-dimensional scale to measure the career expectations of female hotel employees in mainland China. In view of the relative lack of research on the career management of female hotel employees in mainland China, the career expectation measurement scale developed in this study is a necessary and beneficial supplement in the literature and can be used as the basis for future relevant research. This study also has a practical contribution to hotel management and the female employees. This study identified important aspects of career expectations, such as providing good benefits, having time to spend with family after work, having enough time to care for the elderly and children, and so on. Good pay and time guarantee can promote the work performance of female employees. Therefore, the hotel must provide benefits in line with the local average living standard, and formulate measures to effectively ensure that female employees enjoy family time. From the perspective of female employees, clear career expectations and persistent dedication to the hotel industry can lead to greater career achievements.

The limitation of this research is reflected in the fact that the theoretical basis of the dimension of "career expectation of female employees" is not very solid and needs further research. It is necessary to further clarify the differences between the concepts of career expectations, self-efficacy, self-evaluation and career motivation of female employees. 
In conclusion, this study provides a comprehensive overview of the career expectation practices of female hotel employees in mainland China. A seven item Career Expectation Scale (CES) was developed. Two dimensions were found to be reliable, and the two dimensions developed are consistent with the career expectations of female hotel employees in reality. The CES may be broadly used to assess levels of career expectation of female employees in hotels. The most significant contribution of this study is to develop an effective and reliable measurement of career expectations for female employees in the background of the hospitality industry in mainland China. Since career expectations have not been extensively studied in hotels in mainland China, the results of this study can be used as a basis for future research. Future research and utilization in practice will clarify the merits of this new scale.

Author Contributions: Conceptualization, H.S.; methodology, T.L.; writing-original draft preparation, T.L.; supervision, H.S.; formal analysis, K.Y.C.; investigation, X.W.

Funding: This research received no external funding.

Conflicts of Interest: The authors declare no conflict of interest.

\section{References}

1. Geers, A.L.; Weiland, P.E.; Kosbab, K.; Landry, S.J.; Helfer, S.G. Goal activation, expectations, and the placebo effect. J. Personal. Soc. Psychol. 2005, 89, 143-159. [CrossRef] [PubMed]

2. Webster's New World Dictionary of the American Language, 10th ed.; Merriam-Webster: New York, NY, USA, 1995.

3. Woods, R.C. Managing to meet employee expectations: Quality improvement. People Strategy 1993, 16, 13-28.

4. Cleveland, J.N.; O'Neill, J.W.; Himelright, J.L.; Harrison, M.M.; Crouter, A.C.; Drago, R. Work and family issues in the hospitality industry: Perspectives of entrants, managers, and spouses. J. Hosp. Tour. Res. 2007, 31, 275-298. [CrossRef]

5. Oliver, R.L. A cognitive model of the antecedents and consequences of satisfaction decisions. J. Mark. Res. 1980, 17, 460-469. [CrossRef]

6. Pearson, C.A.L. The turnover process in organizations: An exploration of the role of met-unmet expectations. Hum. Relat. 1995, 48, 405-420. [CrossRef]

7. Porter, L.W.; Steers, R.M. Organizational, work, and personal factors in employee turnover and absenteeism. Psychol. Bull. 1973, 80, 151-176. [CrossRef]

8. Chatman, J.A. Improving interactional organizational research: A model of person-organization fit. Acad. Manag. Rev. 1989, 14, 333-349. [CrossRef]

9. Zhao, Y.; Wang, M. Preliminary study on career development of Chinese women. Stat. Inn. Mong. 2007, 3, 37-39.

10. Liu, J. Career barriers and elimination of urban women. J. Shandong Women's Univ. 2009, 6, 16-18.

11. Chen, X. Ceiling phenomenon and the guarantee, cultivation and development of female leadership competence. Adm. Law 2007, 10, 72-74.

12. Lin, J. Study on Career Development Path and Influencing Factors of Hotel Staff. Ph.D. Thesis, The South China University of Technology, Guangzhou, China, 2011.

13. Li, Y. Study on the Improvement of Female Human Resource Quality in Xinyuan Hotel Changsha. Ph.D. Thesis, Xiangtan University, Xiangtan, China, 2014.

14. Fan, X. Research on Career Development Crisis of Female Hotel Department Managers. Ph.D. Thesis, Huaqiao University, Quanzhou, China, 2011.

15. Lin, Q. Research on Career Planning of Women in Hotel Service Industry-A Case Study of Star Hotels in Shandong Province. Ph.D. Thesis, Wuhan Engineering University, Wuhan, China, 2015.

16. Guo, H. The Relationship among Career Aspirations, Personal Evaluation and Social Support of Traditional Chinese Medicine Students. Ph.D. Thesis, Beijing Traditional Chinese Medicine University, Beijing, China, 2003.

17. Li, T. Study on Career Expectation of New Employees in State-Owned Nuclear Power Enterprises. Ph.D. Thesis, Fudan University, Shanghai, China, 2008. 
18. Wu, L.; Li, B. University graduates'occupation expectation and its relevant factors. J. Appl. Psychol. 2001, 7, $18-23$.

19. Ling, W.Q.; Fang, L.L.; Bai, L.G. A study on professional values of college students in China. Acta Psychol. Sin. 1999, 31, 342-348.

20. Kong, H.; Cheung, C.; Zhang, H.Q. Career management systems: What are China's state-owned hotels practising? Int. J. Contemp. Hosp. Manag. 2010, 22, 467-482. [CrossRef]

21. Ng, E.S.; Schweitzer, L.; Lyons, S.T. New generation, great expectations: A field study of the millennial generation. J. Bus. Psychol. 2010, 25, 281-292. [CrossRef]

22. Kong, H.; Cheung, C.; Song, H. Determinants and outcome of career competencies: Perspectives of hotel managers in China. Int. J. Hosp. Manag. 2012, 31, 712-719. [CrossRef]

23. Lou, J.; Shi, P.; Wang, H. A study on the current situation of medium-and high-level managerial professionals in Shanghai's hotels. Tour. Trib. 2003, 18, 70-73.

24. Super, D.E. The Psychology of Careers; An Introduction to Vocational Development; Harper \& Bros: Oxford, UK, 1957.

25. Churchill, G.A., Jr. A paradigm for developing better measures of marketing constructs. J. Mark. Res. 1979, 16, 64-73. [CrossRef]

26. Schriesheim, C.A.; Powers, K.J.; Scandura, T.A.; Gardiner, C.C.; Lankau, J. Improving construct measurement in management research: Comments and a quantitative approach for assessing the theoretical content adequacy of paper-and-pencil survey-type instruments. J. Manag. 1993, 19, 385-417. [CrossRef]

27. Gottfredson, L.S. Applying Gottfredson's Theory of Circumscription and Compromise in Career Guidance and Counseling. In Career development and Counseling: Putting Theory and Research to Work; Brown, S.D., Lent, R.W., Eds.; John Wiley \& Sons Inc.: Hoboken, NJ, USA, 2005; pp. 71-100.

28. Du, Y. A Study on Career Barriers and Countermeasures for Highly Educated Women. Master's Thesis, Xiamen University, Xiamen, China, 2008.

29. Ke, J. Research on Career Barriers and Coping Strategies of Female MBA Students. Master's Thesis, Huazhong University of Science and Technology, Wuhan, China, 2006.

30. Huang, L. Development of Self-Barrier Factor Scale for Women's Career Development. Master's Thesis, Huazhong University of Science and Technology, Wuhan, China, 2010.

31. Fu, X. Research on the Influencing Factors and Effects of Employee Career Expectation. Master's Thesis, Shandong University, Jining, China, 2014.

32. Yang, Z. A Study on the Relationship between Career Expectation, Personality Traits and Employment Pressure of Normal University Students. Master's Thesis, Qufu Normal University, Jining, China, 2010.

33. Liu, X. Relevant Study to Employment Expectation and Satisfaction of College Graduates. Master's Thesis, Sichuan University, Chengdu, China, 2007.

34. Auerbach, C.F.; Silverstein, L.B. Qualitative Studies in Psychology. In Qualitative Data: An Introduction to Coding and Analysis; New York University Press: New York, NY, USA, 2003.

35. Altinay, L.; Paraskevas, P. Data collection techniques. In Planning Research in Hospitality and Tourism, 2nd ed.; Routledge: London, UK, 2008; pp. 107-135. [CrossRef]

36. Zaichkowsky, J.L. Measuring the involvement construct. J. Consum. Res. 1985, 12, 341-352. [CrossRef]

37. Kaiser, H.F. The application of electronic computers to factor analysis. Educ. Psychol. Meas. 1960, 20, 141-151. [CrossRef]

38. Stevens, J.P. Applied Multivariate Statistics for the Social Sciences, 2nd ed.; Erlbaum: Hillsdale, NJ, USA, 1992.

39. Hair, J.F.; Anderson, R.E.; Tatham, R.L.; Black, W.C. Multivariate Data Analysis, 6th ed.; Prentice Hall: Upper Saddle River, NJ, USA, 2002.

40. Kaiser, H.F. An Index of Factorial Simplicity. Psychometric 1974, 39, 31-36. [CrossRef]

41. Field, A. Discovering Statistics Using SPSS, 2nd ed.; SAGE Publications Ltd.: London, UK, 2005.

42. Nunnally, J.C. Psychometric Theory; McGraw-Hill: New York, NY, USA, 1978.

43. Byrne, B.M. Structural Equation Modeling with AMOS: Basic Concepts, Applications, and Programming; Lawrence Erlbaum Associates: London, UK, 2001.

44. Hair, J.F.; Black, W.C.; Babin, B.J.; Anderson, R.E. Multivariate Data Analysis, 7th ed.; Pearson: London, UK, 2009.

45. Anderson, J.C.; Gerbing, D.W. Structural equation modeling in practice: A review and recommended two-step approach. Psychol. Bull. 1988, 103, 411-423. [CrossRef] 
46. Fornell, C.; Larcker, D.F. Evaluating Structural Equation Models with Unobservable Variables and Measurement Error. J. Mark. Res. 1981, 18, 39-50. [CrossRef]

47. Kong, H.; Wang, S.; Fu, X. Meeting career expectation: Can it enhance job satisfaction of Generation Y? Int. J. Contemp. Hosp. Manag. 2015, 27, 147-168. [CrossRef]

48. Wang, S. The Relationships Among Career Aspirations, Professional Commitment and Career Efficacy of College Students. Ph.D. Thesis, Qufu Normal University, Shandong, China, 2009.

49. Wong, S.C.; Siu, V.; Tsang, N. The impact of demographic factors on Hong Kong hotel employees' choice of job-related motivators. Int. J. Contemp. Hosp. Manag. 1999, 11, 230-242. [CrossRef]

(C) 2019 by the authors. Licensee MDPI, Basel, Switzerland. This article is an open access article distributed under the terms and conditions of the Creative Commons Attribution (CC BY) license (http://creativecommons.org/licenses/by/4.0/). 